\title{
Las emociones en el arbitraje femenino en la provincia de Huelva
}

\section{Zahira López-Navarro}

\author{
Graduada en Ciencias de la Actividad Física y del Deporte (Universidad de \\ Huelva) \\ Email: zahiraLN-96@hotmail.com
}

RESUMEN: La desigualdad de género es una realidad en la sociedad, y particularmente dentro del deporte. Este trabajo se centrará en el fútbol y el arbitraje, por ser contextos muy masculinizados. El presente estudio pretendió conocer las dificultades y emociones que experimentan las mujeres dentro del arbitraje y el fútbol. Para conseguir este objetivo se realizaron entrevistas a 5 perfiles diferentes de árbitras de la provincia de Huelva, a través de un guion diseñado con preguntas claves para ver cuál fue el estado de ánimo de estas mujeres durante el partido y tras finalizar este. Además, una de ellas, realizó un diario emocional. Para ello se llevó a cabo una narrativa abierta, focalizada en qué sintieron y qué es lo que causó ese sentimiento. Este escrito se realizó tras la finalización de cada partido, tras haber tenido o no, que soportar diferentes comentarios machistas. Los resultados mostraron que las arbitras que escuchaban numerosos insultos fueron más por su figura que, por la manera en qué pitaban. Por otra parte, en los partidos en los que no había insultos y sí felicitaciones, estaban contentas por ver lo que les satisface su labor. Es necesario acabar con la desigualdad en el mundo del arbitraje, para ello se debe incidir en una formación coeducativa para poder cambiar la actitud de toda la sociedad con respecto al papel de la mujer en el mundo del deporte.

PALABRAS CLAVE: desigualdad, arbitraje, fútbol.

\section{The emotions in the female arbitration in the city of Huelva}

ABSTRACT: Gender inequality is a reality in society, and particularly within sport. This work will focus on football and arbitration, as they are very masculinized contexts. The present study sought to know the difficulties and emotions experienced by women in arbitration and football. To obtain this objective, obtain interviews with 5 different reference profiles of the province of Huelva, through a script designed with key questions to verify the mood of these women during the match and after finishing this. In addition, one of them, made an emotional diary. For this, an open narrative was carried out, focused on what they felt and what caused that feeling. This writing was made after the end of each game, after having had or not, that had different sexist comments. The results that the arbiters who heard many insults were more for their figure than for the way they whistled. On the other hand, in the parties in which there were no insults and congratulations, they were happy to see what satisfies their work. It's necessary to end the inequality in the world of arbitration, for this, a coeducational formation must be influenced in order to change the attitude of the whole society regarding the role of women in the world of sport.

KEY WORDS: inequality, refereeing, football. 


\section{INTRODUCCIÓN}

\subsection{Planteamiento del problema}

La desigualdad de género es algo con lo que hay que actuar, no se tiene como finalidad que sean iguales, es evidente que hombres y mujeres son distintos, lo que se tiene que conseguir es que ambos sexos tengan las mismas oportunidades, es decir, que no haya diferencias a la hora de acceder a cualquier lugar. "No son los dos sexos superiores o inferiores el uno al otro. Son, simplemente, distintos" (Castejón-Bolea, 2013).

Los roles de género, tanto el masculino como el femenino, influyen en las expectativas que se le atribuyen a cada uno de los dos sexos desde que nacemos y que se convertirán en los comportamientos que todos conocemos $\mathrm{y}$, además, aceptamos, diferenciando aquello que dice ser masculino para los hombres y aquello que dice ser femenino para las mujeres. Estos roles se transmiten a niños y niñas, haciendo que cada uno de ellos lo vaya adoptando a un comportamiento que sea masculino o uno que sea femenino. Es evidente que se adaptan al entorno en el que viven, por lo que eso es lo que integrarán a su personalidad. En este sentido, el contexto social (medios de comunicación, familiares, docentes, entrenadores, dirigentes, etc.) puede influir en la eliminación de estereotipos, así como en la promoción y difusión del principio de igualdad. De hecho, se pueden encontrar artículos que estudian el papel de la prensa en la consecución de la igualdad efectiva entre hombres y mujeres en el ámbito deportivo: Calvo-Ortega (2014) encontró una marcada desigualdad entre hombres y mujeres en los informativos deportivos de televisión, que favorecen la perpetuación de estereotipos sexistas; Santillán-Esqueda y Gantús (2010) afirman que a pesar de la irrupción de la mujer en el fútbol, en México se mantuvo la creencia que aquellas mujeres que practicaban o arbitraban se masculinizaban, alterando sus características femeninas, incluida su sexualidad. Por otro lado, hay investigadores que han analizado cómo el profesorado de Educación Física juega un rol importante en el cambio de la cultura escolar con respecto a la igualdad (Piedra, García-Pérez, Fernández-García, y Rebollo, 2014).

La influencia de los estereotipos en la enseñanza de la educación física se puede traducir en una serie de diferencias, tanto de intereses y motivación como en el grado de participación hacia ciertas actividades físicas en función del género (Moreno, Martínez, y Alonso, 2006). A modo de ejemplo, y según Pavón-Lores y Moreno-Murcia (2008), las mujeres muestran una mayor preferencia por las actividades de carácter más cooperativo y menos individualistas, como la expresión corporal, la expresión dramática, los ejercicios por parejas, los multisaltos y los estiramientos. Sin embargo, los intereses de los hombres se centran en actividades de carácter más activo y competitivo.

El deporte femenino conlleva numerosas desigualdades si lo comparamos con el masculino, algunos ejemplos de ello son la remuneración económica (Piedra, 2008), el género masculino cobra el triple que el género femenino, siendo una misma liga, la distribución y asignación de espacios deportivos, vestuarios y otras instalaciones, indumentaria, medios de trasporte para asistir a las competiciones, entre otros.

En muchos casos, aquellas deportistas que alcanzan la élite están sometidas a multitud de factores negativos hacia ellas: psicológicos, materiales, tener que depender de becas, o miedo a la arbitrariedad de sus propios entrenadores que pueden prescindir de ellas sin necesidad de justificar sus acciones, etc. 
En el caso del arbitraje, es inhabitual que una mujer sea juez de un partido. Es común ver como en partidos masculinos al ver que una mujer va a arbitrar les llame la atención y a veces piensen que ni si quiera es ella el árbitro del partido. Según Velasco (2017) para ser árbitro se requiere aptitud (técnica, táctica y física) y actitud. La mujer, por cuestiones biológicas, puede tener una menor aptitud física respecto al hombre, sin embargo, es innecesario comparar, simplemente para dedicarse al arbitraje es necesario que tanto hombres como mujeres mantengan una buena condición física (algo que se consigue con un entrenamiento adecuado, independientemente del género).

Viendo todo esto, es crucial conocer los obstáculos que sienten las mujeres árbitras cuando realizan alguna de las actividades conocidas para "hombres" y la necesidad de proponer soluciones.

\subsection{Marco teórico}

El arbitraje se presenta como uno de los campos menos explorados desde la Psicología de la Actividad Física y el Deporte, a pesar de ser este colectivo fundamental para la práctica del deporte. Este no se puede entender sin la figura de un árbitro, ya que será el que controle esta práctica a través de un reglamento formal. Según Díaz (1999, citado por Guillén, 2006), un árbitro o juez deportivo, según sea el caso:

1. Decide si se cumple el reglamento y sanciona si es preciso.

2. Valora lo que está haciendo el deportista.

3. Evalúa la ejecución del deportista.

4. Transforma la ejecución del deportista en un dato numérico.

5. Aplica los criterios cualitativos y cuantitativos, así como las sanciones o bonificaciones que se contemplen en el reglamento

Según Slack, Maynard, Butt y Olusoga (2013) esta profesión supone una actividad donde las variables psicológicas juegan un papel fundamental. Con ello, queda claro que no entra en juego sólo el ámbito físico y/o técnico, sino que los aspectos psicológicos de cada uno de los/as árbitros/as es muy importante para que puedan realizar bien su trabajo.

Como dicen Pedrosa y García-Cueto (2015) es socialmente reconocida la presión constante a la que los árbitros son sometidos, no sólo por los propios deportistas y entrenadores, sino también por los aficionados. Muchos de los estudios que se han realizado vienen dados por la situación en la que se encuentran gran cantidad de árbitros en un partido y tras este. Esta situación es producto de la dificultad en la que se ven inmersos en la actividad arbitral, por ello es importante tener en cuenta la ansiedad y el estrés que padecen en esos momentos. Al estar sometidos a tan elevada presión dentro y fuera del terreno de juego, necesitan de un apoyo social que atenúe las exigencias que les imponen en cada uno de los partidos y también fuera de ellos, ya que, una vez terminado su labor de árbitro en el campo, tienen que ser constantes, entrenar día tras día para tener una buena forma física, estudiar el reglamento (que sufre algunas modificaciones año tras año), etc. El estrés y la ansiedad que se reproduce en cada uno de los partidos es un dato importante para ver cómo actúa un árbitro ante diversas dificultades.

Analizando varios trabajos encontramos diferentes variables que influyen en la toma de decisiones de los árbitros como puede ser: 
- La percepción subjetiva del juego (Scoppa, 2008).

- La presión que se encuentra por parte del público (Dohmen, 2008).

- El influjo de diferentes estresores relacionados con el juego y, el entorno más próximo al árbitro (Pettersson-Lidbom y Priks, 2010).

Con el paso del tiempo, diversos árbitros pueden caer en el síndrome de burnout. Según Freud (1974, citado por López-Elizalde, 2004), se trata de un síndrome en el que se observó que, al año de trabajar, la mayoría sufría una progresiva pérdida de energía, hasta llegar al agotamiento, síntomas de ansiedad y de depresión, así como desmotivación en su trabajo, siendo el género femenino, el grupo más vulnerable.

Entre los factores considerados como los más generadores de estrés hacia los árbitros, según Anshel y kaissidis (1997, citado por Guillén y Bara, 2004), están el miedo al fracaso, el daño físico, el cansancio físico y mental, fallar en momentos decisivos, conflictos interpersonales, presión debida al tiempo, miedo a los errores, conflictos con la prensa, espectadores y jugadores.

En general, la actividad de los árbitros en el fútbol está asociada con diferentes condiciones que generan estrés psicológico, que como se ha hablado anteriormente pueden ser las críticas por parte de los entrenadores, jugadores, medios de comunicación y fanáticos, así como la rabia de los entusiastas que comúnmente creen que ellos tienden a "perseguir" su equipo (Balch y Scott, 2007). Dentro de este contexto de "hombres", las mujeres se cruzan con diferentes problemas, ser árbitra y principalmente, ser mujer, ya que actualmente vemos una gran desigualdad dentro del deporte. En esta línea, la ansiedad y el estrés puede afectarlas más, puesto que además de encontrarse con insultos hacia esta profesión, se encuentran con una violencia machista hacia su persona.

Según algunos autores como De Coubertin (1979), el hecho de que el deporte fue creado por y para los hombres, ya en el inicio de las Olimpiadas Modernas manifestaba un rechazo absoluto hacia la participación de la mujer en el deporte, indicando que las mujeres sólo tenían una función en el deporte, la cual era coronar al vencedor con las guirnaldas del triunfo. Aunque esto sucedió hace muchos años, la discriminación que ha sufrido la mujer a lo largo de la historia, sigue hoy día vigente en determinadas actitudes y estereotipos. En el arbitraje femenino es muy común, puesto que siempre ha sido para hombres donde ellos representaban la fortaleza, mientras que la mujer representaba la belleza y la sensualidad, es por esto, el que hace un tiempo atrás, parecía escandaloso que una mujer fuera juez en un terreno de juego donde participaban hombres. Según Santillán-Esqueda y Gantús, (2010), las mujeres se les percibía y se les percibe aún, aunque en menor medida, como transgresoras de las condiciones y valores sociales que debían definirlas como sujetos: ternura, pasividad, debilidad y docilidad.

Si bien en las últimas décadas se han alcanzado importantes logros en este ámbito, no puede ignorarse la tenaz persistencia de enormes desigualdades y discriminaciones contra ellas. Esto se debe, en parte, a que muchas transformaciones han sido en realidad cambios que continúan marcados por la predominancia de lo masculino y en que la categoría universal desde la cual se analiza y decide -bajo una supuesta neutralidad- sigue siendo el hombre y lo masculino (Mukhopadhyay y Singh, 2008).

Según Fernández (2007) la sociedad y la cultura reproducen patrones tradicionales de roles de género; éstos están signados por la desigualdad y la 
asimetría de poder y tienden a actuar en detrimento de las posibilidades de las mujeres. Estos patrones están profundamente introyectados como modelos, principios y actitudes. Por lo que cabe destacar, que el tema de la desigualdad está impregnado en todos los ámbitos de la vida, en el que el hombre es superior a la mujer. Dentro del deporte, quizá se puede ver más claro, puesto que incluso dentro de los medios de comunicación se transmiten estereotipos que coartan la libertad de elección.

Otro agente de socialización muy importante son los medios de comunicación de masas. Estos cada vez tienen más importancia en el proceso de socialización. Determinados medios muestran un modelo de mujer muy alejado de la práctica deportiva: ligera de ropa o simplemente desnuda, prototipo destinado, al parecer, a atraerse a un tipo de lectores más interesados por las publicaciones de contenido abiertamente machista que por la información estrictamente deportiva (Ibáñez, 2001). Por lo que continuamente, vemos como la información destinada al deporte femenino es de poca categoría y mala, ya que gran parte de estas informaciones expone a la mujer como objeto, anteponiendo las anécdotas a lo que verdaderamente consiguen.

La influencia que tienen los medios en todos los ciudadanos es algo indiscutible. $Y$ aun sabiendo esto, siguen condicionando los modelos de masculinidad y feminidad que transmiten. Muchos medios de comunicación diferencian lo que se tiene que esperar de cada uno en función del sexo al que se pertenezca. Por lo general, lo femenino es "menos" o "peor" que lo masculino. El deporte espectáculo es masculino, el deporte que da más juego es masculino, el deporte que más dinero deja es masculino, el deporte mejor pagado es masculino... Es por ello que continuadamente se ve en la tele el resumen de todos los deportes, pero el tiempo dedicado al deporte femenino es casi inexistente (Calvo-Ortega, 2014).

Por tanto, aunque, la sociedad está cambiando cada vez más y se pueden ver los logros de las mujeres en determinadas noticias, sigue habiendo desigualdad en este ámbito, puesto que a lo que se refiere, el género masculino sigue teniendo mayor parte por los medios de comunicación que el femenino. Es por ello que, el que las chicas practiquen menos fútbol, les cueste ejercer de juez en los diversos partidos y se sientan menos valoradas, está también vinculado a la inexistencia 0 baja representación en los medios de comunicación. Para ello sería una buena idea el que los medios de comunicación se impliquen más con el deporte y la mujer, ya que son ellas, las que están consiguiendo muchísimos logros, con esto, lograríamos que se difundiera más y la sociedad cambiara su manera de pensar con respecto a este tema.

\subsection{Objetivos}

En base a este problema de investigación, se plantearon tres principales objetivos:

- Describir las dificultades que experimentan las árbitras por el hecho de ser mujeres.

- Conocer qué sienten las mujeres árbitras durante los partidos

- Proponer soluciones en base a lo estudiado.

\section{MÉTODO}

\subsection{Participantes}


El número de participantes en el estudio fue de 5 , que supone el total de la población de árbitras femeninas en la provincia de Huelva. Para ello, se siguieron las directrices éticas y legales vigentes en cuanto a investigación con seres humanos y protección de datos personales. Todas eran árbitras colegidas en esta misma provincia y con las características que se muestran a continuación:

- Participante 1. Mujer de 22 años de edad, cursaba 4ํㅡㄹ de Ciencias de la Actividad Física y el Deporte, ha dirigido sus estudios a la mención de salud. Su lugar de procedencia es Córdoba y estudia este grado en la Universidad de Huelva. La categoría a la que pertenece dentro del arbitraje es oficial.

- Participante 2. Mujer de 24 años de edad, actualmente trabaja en un colegio como monitora de actividades deportivas y como monitora de atención a la diversidad. Estudió el TAFAD y estaba ampliando su formación realizando el Grado en Educación Primaria con doble mención (Educación Física y Educación Especial) en la Universidad de Huelva. La categoría a la que pertenece dentro del arbitraje es oficial.

- Participante 3. Mujer de 20 años de edad, que en el momento de la realización de este estudio cursaba $2^{\circ}$ de Administración y Dirección de Empresas. Su procedencia es de Jaén, pero estudia este grado en la Universidad de Huelva. La categoría a la que pertenece dentro del arbitraje es oficial.

- Participante 4. Mujer de 26 años de edad, Graduada en Educación Primaria con la especialidad en Educación Física. Se encontraba realizando el Máster de Investigación en Educación Física y Ciencias del Deporte de la Universidad de Huelva. La categoría a la que pertenece dentro del arbitraje es provincial.

- Participante 5. Mujer de 22 años de edad, que estaba opositando al Cuerpo Nacional de Policía. Su procedencia es de Huelva. La categoría a la que pertenece dentro del arbitraje es provincial.

\subsection{Instrumentos}

\subsubsection{Entrevista}

Para llevar a cabo la investigación, el elemento que se utilizó fue una entrevista. Según Díaz-Bravo, Torruco-García, Martínez-Hernández y Varela-Ruiz (2013) la entrevista un instrumento técnico de gran utilidad para recabar datos y que se emplea en la investigación cualitativa.

Se trató de una entrevista de preguntas abiertas. En ésta, se hacen preguntas que fueron redactadas anteriormente y que siguieron un orden previsto. Para realizar las preguntas se partieron de objetivos anteriormente propuestos, donde cada una de esas preguntas fueron encaminadas a la respuesta de esos objetivos, dando estas, informaciones sobre sus pensamientos, sentimientos y actitud a cada una de las situaciones que puedan surgir. Para ello se realizaron 8 preguntas, las cuales se pueden agrupar de dos en dos sobre el tema al que se refiere. Las dos primeras preguntas se refieren a cómo le llevó a querer iniciarse en este mundo; la tercera y la cuarta son las 
dificultades que se han podido encontrar por el hecho de ser árbitra y mujer; la quinta y la sexta las emociones que sienten tras los partidos; y las dos últimas, las posibles soluciones que puede plantear cada sujeto entrevistado.

Las cuestiones que se llevaron a cabo con los sujetos fueron las siguientes:

1. ¿Cómo se inició en este mundo?

2. ¿Qué opina sobre el machismo en el fútbol? ¿Cómo considera que son las agresiones, hacia los árbitros o hacia la mujer?

3. ¿Qué dificultades ha tenido durante la formación por el hecho de ser mujer?

4. ¿Qué tipo de dificultades ha encontrado en su experiencia como arbitra? ¿Qué tipo de rostro percibe cuando llega al campo y ven que es una mujer?

5. ¿Cómo se siente durante un partido? (cuando oye que agreden verbalmente con frases amenazantes, despectivas o insultos).

6. ¿Qué emociones siente tras este?

7. ¿Qué le funciona para superar emocionalmente los malos momentos?

8. ¿Qué soluciones cree que hay para que mejore esta situación?

\subsubsection{Diario}

Otro instrumento utilizado para llevar a cabo esta investigación fue el diario. La realización de este diario lo hizo la participante 4, la cual, tras cada partido se le solicitó que compartiera todas sus vivencias, tanto de carácter positivo como negativo, a la vez que expresara los sentimientos que tenía en cada uno de esos momentos y cuál era la causa de ello. Según Maura (2006) el diario constituye un valioso instrumento para el diagnóstico del desarrollo personal, toda vez que permite la expresión de las vivencias y reflexiones acerca de su desempeño en el ejercicio que se plantee.

Con el diario se pretendió que este sujeto trabajara con un carácter abierto, para que expresara libremente sus impresiones, todo esto lo llevó a cabo a través de su autobservación en los partidos y cómo fue capaz de resolver los diferentes conflictos que se le plantearon.

\subsection{Procedimiento}

\subsubsection{Entrevista}

En primer lugar, se definieron los objetivos que queríamos llevar a cabo en nuestra investigación y tras esto, se planteó la guía a seguir para realizar la entrevista que se le haría a las árbitras con sus respectivas preguntas. Posteriormente, se contactó con las cinco participantes que se entrevistaron, que residían en ese momento en Huelva para conocer su disponibilidad para participa en el estudio. Tras esto, se acordó la fecha y lugar donde se realizaría la entrevista. Una vez planteado, el día de la entrevista, se tuvo preparada una grabadora para dejar guardada toda la información comentada en el análisis. 


\subsubsection{Diario}

Se contacto con una de las participantes y se le propuso si podría realizar un diario, en el que expresara sus sentimientos de todos los partidos en los que fuera a arbitrar. Para realizar el diario debía de escribir cómo se sentía justo tras el partido, para que expresase realmente lo que siente y no olvidara nada. Dicha participante aceptó y facilitó un diario donde sobre diez partidos donde expuso sus reflexiones.

\subsection{Análisis de los datos}

\subsubsection{Entrevista}

Recabada toda la información del tema, se escucharon los audios y se transcribieron a ordenador todas las entrevistas realizadas en formato Word (se pueden consultar en Anexos).

Después de transcribir la entrevista, las respuestas se clasificaron en cada una de las preguntas, reubicando las que correspondían a otras. Posteriormente, se realizó un análisis de contenido de las respuestas a cada pregunta y se extrajeron los resultados de cada una. Este proceso de codificación y análisis de contenido fue realizado por la autora del trabajo y un profesor universitario experto en este procedimiento.

\subsubsection{Diario}

Una vez entregadas las reflexiones realizadas por la participante, se analizaron las emociones positivas y negativas que había experimentado y cuáles fueron las causas para llegar a eso. Para ello, se realizó una tabla en la que se expresaron los resultados de los 10 partidos arbitrados, juntos con emociones positivas y negativas al igual que las causas (estas reflexiones se adjuntan en Anexos). Para finalizar, se comparó cada uno de los partidos para ver que tenían en común la positividad o la negatividad que se reflejaba en esas reflexiones con la clase de partido arbitrado.

\section{RESULTADOS}

En este apartado se muestran las consideraciones, pensamientos e ideas que tuvieron las participantes ante las cuestiones planteadas anteriormente, además de ver cuáles fueron las emociones que sintieron tras el partido y cuáles fueron las causas que los provocaron. Todas las respuestas se pueden consultar en una tabla en los Anexos.

\subsection{Entrevista}

Pregunta 1: ¿Cómo se inició en este mundo?

En todas las respuestas las participantes coinciden que empezaron en este mundo por ayuda de alguien. La primera participante gracias a la ayuda de su entrenador, la segunda por la pareja de una amiga que es árbitro, la tercera por un amigo de la carrera que estaba metido en este mundo, la cuarta por su novio que también es árbitro y le animó, y la quinta participante, por un familiar. Además, todas tienen en 
común que les gusta el fútbol, tanto la primera participante como la últimoa siguen practicando este deporte, es decir, están federadas, mientras que las participantes dos, tres y cuatro nunca han estado federadas, y aunque no lo han practicado siempre les ha gustado.

Pregunta 2: ¿Qué opina sobre machismo en el fútbol? ¿Cómo consideras que son las agresiones, hacia los árbitros o hacia la mujer?

Todas coinciden que el tema del machismo se ha ido suavizando, aunque aún hay mucho por hacer. Cada una de las participantes comparten la idea de que el machismo está presente en el deporte en general, pero más aún en el fútbol por ser considerado para "hombres". Cabe destacar lo que dice la participante 4, al igual, que las demás, ha sufrido mucho machismo por parte de la grada o de los propios futbolistas. Se sorprende como, incluso las propias madres de los niños, lo han hecho, han criticado a una árbitra por el simple hecho de ser mujer. La participante 5 a diferencia de la participante 1, que también estaba federado en este deporte, compara como en el arbitraje sufre más machismo que siendo futbolista. Con respecto a los insultos que reciben todas, dicen que el machismo que se produce en el momento en el que ellas arbitran es contra la mujer, pues todos los insultos son hacia la figura femenina.

Pregunta 3: ¿Qué dificultades ha tenido durante la formación por el hecho de ser mujer?

En esta pregunta hay variedad de respuesta, cuatro de las cinco árbitras consideran que han tenido dificultades. Al contrario que éstas, la participante 3 expone que no ha tenido dificultades en su formación como árbitra. Las dificultades que han experimentado la participante 1, 4 y la 5 fueron por terceras personas, aquellas, que aun viviendo en ese mundo se lo hacen más difícil por no querer que piten ellas ciertos partidos o por como dice la participante 5, "no molestarse en ayudarte cuando lo necesitas". La participante 2, a diferencia de las demás, las dificultades que ha sufrido han sido de tipo físico, por la dificultad que tenían las pruebas cuando ella empezó a arbitrar.

Pregunta 4: ¿Qué tipo de dificultades ha encontrado en su experiencia como arbitra? ¿Qué tipo de rostro percibe cuando llega al campo y ven que es una mujer?

Todas las árbitras comienzan hablando de la existencia de dificultades, excepto la participante 3, la cual, empieza hablando que no ve dificultades a la hora de arbitrar, pero conforme avanza, expone motivos que para las demás sí fueron dificultades, puesto que piensa en el "qué dirán" de antes de un partido cuando ven a una mujer. Tanto la participante 1 como la 2 coinciden en la falta de tiempo requerido para entrenar, añadiendo la participante 2 la falta de tiempo para poder estudiar el reglamento. Las participantes 4 y 5 hablan, a diferencia de las participantes 1 y 2, de las dificultades por los comentarios machistas que reciben, del tipo: "una mujer no debería estar pitando partidos de hombres". Además, en lo que todas coinciden, es en la cara de sorpresa que se ve en los demás, tanto padres, jugadores, y entrenadores, por el hecho de verles en un partido, aunque la participante 2, destaca, "ya es menor la cara de sorpresa de los demás, puesto que, al ser pocas árbitras en la provincia de Huelva, los equipos van conociéndonos".

Pregunta 5: ¿Cómo se siente durante un partido? (cuando oye que le agreden verbalmente con frases amenazantes, despectivas o insultos) 
En este caso, la participante 1 y 5 coinciden en que parece que los árbitros no pueden equivocarse en ningún momento, en que como los demás ellos también son personas. Las demás participantes coinciden en que hay mucha falta de educación y poca coherencia con lo que dicen. Lo que diferencia a la participante 5 de los demás es que al llevar más años arbitrando llega un momento en el que le da igual las críticas de los demás, se centra en su partido, sin que le perjudiquen los comentarios.

Pregunta 6: ¿Qué emociones siente tras éste?

Las respuestas fueron variadas, para la participante 1 es inseguridad lo que le provoca, esto puede ser porque está empezando y como ha dicho anteriormente la participante 6 en la anterior pregunta, al principio siempre afecta más, también siente rabia e impotencia, por lo que coincide con la participante 2. Sin embargo, las participantes o árbitras 3 y 5 olvidan lo sucedido en el partido y se sienten a gusto tras éste. Mientras que la participante 4 tiene en común que tras el partido se siente bien por hacer un buen partido, a pesar de todas las críticas recibidas; pero se diferencia con la anterior, que en ocasiones las críticas sí que le afecta y le hace replantearse si de verdad vale para este mundo.

Pregunta 7: ¿Qué le funciona para superar emocionalmente los malos momentos?

Aquí, encontramos que todas las participantes dijeron lo mismo, todas superaron sus malos momentos pensando en cómo se iniciaron ahí, en los momentos positivos vividos que valen más que los negativos, en lo que les gusta ese mundo, además la participante 5 incluye el gran apoyo que tiene de sus compañeros más cercanos.

Pregunta 8: ¿Qué soluciones cree que hay para que mejore esta situación?

En esta pregunta todas exponen soluciones que se deberían llevar a cabo en esta sociedad, menos la participante 4 , la cual, expresa que no hay soluciones, ya que siempre va a haber alguien que crea que una mujer no puede arbitrar. Y piensa que lo que se tiene que hacer es motivar a las mujeres para que se inicien más en este mundo y que vean los demás que las mujeres también son capaces y tienen las mismas oportunidades de intentarlo que cualquier otro. Por el contrario, tanto las participantes 1 , 2 y 5 piensan que es cuestión de educación en la sociedad, además para la participante 1, "tienen que empezar cambiando la manera de pensar las propias mujeres, ya que ellas son a veces las que insultan a la propia árbitra por el hecho de ser mujer". Además, la participante 1 dice lo mismo que la participante 2, ambas ponen de manifiesto los medios de comunicación deberían de apoyar más el deporte femenino, ya que son mayoritariamente los hombres los que salen en la sección de deporte. En esta pregunta, la participante número 4, diferenciándose de lo que dicen las demás con respecto a la sociedad, se ha referido en lo que puede hacer ella misma, valorando su esfuerzo y sacrifico en todo lo que hace.

\subsection{Diario}

Los resultados extraídos de las reflexiones escritas en el diario después de los diez partidos se presentan a continuación (se puede consultar la información del diario en el Anexo, así como una tabla resumen con las emociones sentidas tras el partido). 
De estos 10 partidos, en cinco de ellos la árbitra ha experimentado emociones positivas y en otros cinco, negativas. Según la que escribió la árbitra, as emociones positivas no son tan variadas como las negativas. En dos de los partidos ha sentido felicidad, uno por ver a los niños pequeños a los que arbitraba, disfrutar y otro por encontrarse con entrenadores que educan a sus jugadores sin importar demasiado el resultado. En otro de los partidos alegría, ya que recibió felicitaciones por parte de ambos equipos a los que arbitró. Por el contrario, también surgió la otra cara del arbitraje, donde aparecieron emociones negativas, el momento en el que siente impotencia por la cantidad de protestas que recibió en ese partido y por numerosas recriminaciones hacia su persona. Además, en uno sintió miedo, ya que los jugadores les estaban esperando a la salida y se encararon contra los tres árbitros. También es muy "normal" encontrarse con padres de jugadores insultando al entrenador contrario, lo que provoca tristeza o como es más habitual, juzgando el trabajo del árbitro, provocando inseguridad por estar durante 90 minutos de partido así. También hay veces que se encuentra con muy pocas protestas, las que puede generarse por la tensión que crea el fútbol pero que no van a más; por lo que le causa satisfacción comprobar que hace bien el trabajo y muchos partidos termina emocionada al ver, lo que le gusta ese mundo.

\section{DISCUSIÓN}

En este estudio se pretendían describir las dificultades que experimentan las árbitras por el hecho de ser mujeres, conocer que sienten las mujeres árbitras durante los partidos y proponer soluciones en base a lo estudiado.

En los resultados obtenidos de las participantes de esta propuesta investigativa y contrastándolo con otros autores, se ha observado que se coincide con la idea que muestran Santillán y Gantús (2010), en el que se ve a la mujer como las transgresoras de las condiciones y valores sociales que debían definirlas como sujetos: ternura, pasividad, debilidad y docilidad. Todas las árbitras cuando hicieron la entrevista comentaron que el fútbol se sigue viendo para hombres, estando este más valorado para ellos. De hecho, se puede comprobar como en el pasado se pensaba eso, como ejemplo de ello se encuentra De Coubertin (1979), quien expuso el hecho de que el deporte fue creado por y para los hombres, ya en el inicio de las Olimpiadas Modernas manifestaba un rechazo absoluto hacia la participación de la mujer en el deporte, indicando que las mujeres sólo tenían una función en el deporte, y esta era coronar al vencedor con las guirnaldas del triunfo. Aunque afortunadamente esta opinión esta obsoleta (queda alejada de la realidad por el tiempo que ha pasado con respecto a esa fecha), es necesario que se sigan realizando cambios en la sociedad para que la igualdad en todos los contextos sea un hecho.

Slack, Maynard, Butt y Olusoga (2013) expusieron que esta profesión supone una actividad donde las variables psicológicas juegan un papel fundamental. En este caso, podemos ver esta teoría en la participante 4, la cual dice: "Siento rabia y frustración por no poder decirle a esas personas que sean coherentes con lo que dicen". "En ocasiones te hacen replantearte si de verdad sirves para esto, y si merece la pena aguantar todas las críticas e insultos". Como bien dicen Pedrosa y García-Cueto (2015) es socialmente 
reconocida la presión constante a la que los árbitros son sometidos, no sólo por los propios deportistas y entrenadores, sino también por los aficionados.

Según Cruz (1997) una propuesta de mejora para que las árbitras estén formadas en todos sus sentidos, requiere una preparación específica del control de las emociones, a la cual pocas árbitras dedican la atención suficiente. Una de las árbitras, exactamente la participante 4, expresa: "inseguridad, tras escuchar tantos fallos que dicen que se están cometiendo, rabia e impotencia".

Los resultados de este estudio han mostrado que es necesario acabar con la desigualdad en el arbitraje del fútbol, para ello se debería incidir en una formación coeducativa para poder cambiar la actitud de toda la sociedad con respecto al papel de la mujer en el mundo del deporte. Para ello, hay que hacer esfuerzos para poder tener éxito como sociedad, desde el contexto educativo hasta el de los medios de comunicación deben poner su granito de arena. En este sentido, en el contexto educativo Fernández y Piedra (2010) ya han mostrado como un programa de formación coeducativo en los futuros docentes, puede ayudar a la erradicación de las discriminaciones y estereotipos sexistas en la enseñanza, afectando a gran parte de la sociedad. Este tipo de programas podrían implementarse en la formación de entrenadores, árbitros, etc.

Por último, este trabajo presenta algunas limitaciones, como que había una escasez de árbitras en la provincia de Huelva, por lo que como perspectiva de futuro sería interesante ampliar la muestra del estudio con árbitras de otras provincias andaluzas o de otras comunidades autónomas. Para ello, también podría plantearse un diseño de estudio cuantitativo, para poder llegar a través de un cuestionario al máximo número de personas de este colectivo. Además, se deberían realizar más estudios sobre este tema para que la sociedad sea consciente de lo que las mujeres árbitras viven partido tras partido, día tras día.

\section{CONCLUSIONES}

En este apartado, se han tratado de responder a los objetivos del estudio. El primer objetivo del estudio fue "describir las dificultades que experimentan las árbitras por el hecho de ser mujeres". En este sentido, se pudo comprobar que las mujeres sufren muchísimas desigualdades. A pesar de los numerosos cambios sociales y culturales con todo aquello que envuelve a la mujer, en la igualdad de género y en sus derechos, la situación sigue siendo desfavorable para aquellas que se quieren iniciar o están dentro del mundo del deporte, y en concreto, en el fútbol, donde se ha visto que se producen más desigualdades. Hay que tener presente también la presión social y familiar, donde no siempre el arbitraje femenino es valorado por la falta de cultura deportiva que se tiene. Es por ello, que, aunque se va progresando, aún, estas chicas cuentan con la dificultad de tener que escuchar comentarios machistas por el simple hecho de ser mujer y gustarles el fútbol. En este sentido, la sociedad va avanzando, pero no lo suficiente para que exista la igualdad en todos los sentidos.

El siguiente propósito fue "conocer qué sienten las mujeres árbitras durante los partidos". La respuesta de los sujetos fue rica en matices en el contexto de experiencias 
emocionales, tanto dentro como fuera del terreno. Por las reflexiones de una de las árbitras y por las entrevistas realizadas a todas, se pudo extraer que cada partido tiene algo nuevo, que todos los partidos no son malos o todos no son buenos, sino que al meterse en este mundo la idea que tienen es que si se metieron ahí fue por algo. En concreto, arbitran porque verdaderamente les gusta, independientemente de las críticas y los insultos que tienen que escuchar por el simple hecho de ser mujer; eso es lo que les hace replantearse muchas veces el seguir; pero cuando tienen un partido bueno, les motiva para seguir, además de las ganas y la ilusión de que la sociedad vaya cambiando.

En cuanto a proponer soluciones, las respuestas van claramente encaminadas a una mejora de la educación de la sociedad, para ser capaces de ver que las mujeres también pueden llegar lejos en aquellos aspectos o en aquel mundo en el que siempre había sido considerado para hombres.

Como conclusión final, los resultados de este estudio han mostrado que es necesario acabar con la desigualdad en el mundo del arbitraje, para ello se debería incidir en una formación coeducativa para poder cambiar la actitud de toda la sociedad con respecto al papel de la mujer en el mundo del deporte.

\section{REFERENCIAS}

Balch, M. J., y Scott, D. (2007). Contrary to Popular Belief, refs Are People Too! Personality and Perceptions of officials. Journal of Sport Behavior, 30(1), 3-16.

Calvo-Ortega, E. (2014). La representación de la mujer y los roles de género en los informativos deportivos de televisión. Fonseca, Journal of Communication, 8, 111129.

Castejón-Bolea, R. (2013). Marañón y la identidad sexual: biología, sexualidad y género en la España de la década de 1920. Arbor, 189(759), a005. doi: http://dx.doi.org/10.3989/arbor.2013.759n1004

Cruz, J. (1997). Asesoramiento psicológico en el arbitraje y juicio deportivos. En J. Cruz (Ed.), Psicología del deporte (pp. 245-269). Madrid: Síntesis.

De Coubertein, P. (1979). Olympic memoirs. Lausanne: International Olympic Commitee

Díaz-Bravo, L., Torruco-García, U., Martínez-Hernández, M., y Varela-Ruíz, M. (2013). La entrevista, recurso flexible y dinámico. Metodología de investigación en educación médica. Revista Investigación en Educación Médica, 2(7), 162-167.

Dohmen, T. J. (2008). The Influence of Social Forces: Evidence from the Behavior of Football Referees. Economic Inquiry, 46(3), 411-424.

Fernández, E., y Piedra, J. (2010). Efecto de una formación coeducativa sobre las actitudes hacia la igualdad en el futuro profesorado de Educación Primaria. Cultura, Ciencias y Deporte, 5(15), 151-158. 
Guillén, F., y Bara, M. (2004). La ansiedad rasgo y estado entre árbitros de diferentes modalidades deportivas y no árbitros. Revista de Entrenamiento Deportivo, 18,1925 .

Guillén, F. (2006). La psicología del arbitraje y del juicio deportivo. En Psicología y deporte (pp. 667-684). Murcia: DM.

Ibáñez, E. (2001). Información sobre deporte femenino: el gran olvido. Apunts. Educación Física y Deportes, 3(65), 111-113.

López-Elizalde, C. (2004). Síndrome de burnout. Revista Mexicana de Anestesiología, $27(1), 131-133$.

Maura, V. G. (2006). El diario como instrumento de diagnóstico y estimulación del desarrollo profesional del profesorado. Revista Iberoamericana de Educación, 38(2), 1-15.

Moreno, J. A., Martínez, C. y Alonso, N. (2006). Actitudes hacia la práctica físicodeportiva según el sexo del practicante. Revista Internacional de Ciencias del Deporte, 2(3), 20-43. doi:10.5232/ricyde2006.00302

Pavón-Lores, A., y Moreno-Murcia, J. A. (2008). Actitud de los universitarios ante la práctica físico-deportiva: diferencias por géneros. Revista de Psicología del Deporte, 17(1), 7-23.

Pedrosa, I., y García-Cueto, E. (2015). Aspectos psicológicos en árbitros de élite: ¿afecta el salario a su bienestar emocional? Revista de Psicología del Deporte, 24(2), 241-248.

Pettersson-Lidbom, P., y Priks, M. (2010). Behavior under social pressure: Empty Italian stadiums and referee bias. Economics Letters, 108(2), 212-214.

Piedra, J. (2008). Discriminaciones económicas de las mujeres en el deporte de alto nivel. En IV Congreso Internacional y XXV Nacional de Educación Física (Córdoba, 2-5 de abril de 2008).

Piedra, J., García-Pérez, R., Fernández-García, E., y Rebollo, M. A. (2014). Brecha de género en educación física: actitudes del profesorado hacia la igualdad. Revista Internacional de Medicina y Ciencias de la Actividad Física y el Deporte, 14(53), 121.

Santillán-Esqueda, M., y Gantús, F. (2010). Transgresiones femeninas: futbol. Una mirada desde la caricatura de la prensa, México 1970-1971. TZINTZUN: Revista de Estudios Históricos, 52, 141-174.

Scoppa, V. (2008). Are subjective evaluations biased by social factors or connections? An econometric analysis of soccer referee decisions. Empirical Economics, 35, 123140. 
Slack, L. A., Maynard, I. W., Butt, J., y Olusoga, P. (2013). Factors Underpinning Football Officiating Excellence: Perceptions of English Premier League Referees. Journal of Applied Sport Psychology, 25(3), 298-315.

Velasco, M. (2017). Arbitraje femenino: Técnica a la desigualdad. Recuperado: 7/05/2018 de http://planetacb.com/arbitraje-femenio-tecnica-ladesigualdad/

\section{ANEXOS}

\section{Entrevistas}

Esta tabla se presenta la transcripción de los audios obtenidos en las entrevistas

\begin{tabular}{|c|c|c|c|c|c|}
\hline & Participante 1 & Participante 2 & Participante 3 & Participante 4 & Participante 5 \\
\hline $\begin{array}{l}\text { 1. ¿Cómo se } \\
\text { inició en este } \\
\text { mundo? }\end{array}$ & $\begin{array}{l}\text { Llevo desde } \\
\text { pequeña } \\
\text { jugando al fútbol } \\
\text { y siempre me ha } \\
\text { Ilamado la } \\
\text { atención el } \\
\text { arbitraje. Un día, } \\
\text { jugando un } \\
\text { partido, le dije a } \\
\text { mi entrenador } \\
\text { que quería ser } \\
\text { árbitra y ahí } \\
\text { empezaron } \\
\text { todos los pasos } \\
\text { para empezar } \\
\text { con esta nueva } \\
\text { etapa, con } \\
\text { ayuda de mi } \\
\text { entrenador. }\end{array}$ & $\begin{array}{l}\text { La pareja de } \\
\text { una amiga } \\
\text { llevaba dos } \\
\text { años } \\
\text { colegiados, nos } \\
\text { ofreció probar } \\
\text { la experiencia } \\
\text { ya que esto } \\
\text { ocurrió en los } \\
\text { inicios de la } \\
\text { potenciación } \\
\text { del fútbol } \\
\text { femenino. } \\
\text { Siempre me ha } \\
\text { gustado el } \\
\text { deporte y en } \\
\text { especial el } \\
\text { fútbol, aunque } \\
\text { federada nunca } \\
\text { llegué a } \\
\text { practicarlo }\end{array}$ & $\begin{array}{l}\text { Inicié por interés } \\
\text { y curiosidad de } \\
\text { cómo sería este } \\
\text { mundo. } \\
\text { Además, me } \\
\text { habían hablado } \\
\text { de que hay muy } \\
\text { buena sintonía } \\
\text { entre todos los } \\
\text { que lo forman. }\end{array}$ & $\begin{array}{l}\text { Por la } \\
\text { influencia de } \\
\text { amigos de la } \\
\text { carrera que } \\
\text { estaban } \\
\text { estudiando y } \\
\text { que eran } \\
\text { árbitros de } \\
\text { fútbol. } \\
\text { Además, } \\
\text { implicaba } \\
\text { hacer deporte } \\
\text { y ganar algo } \\
\text { de dinero. }\end{array}$ & $\begin{array}{l}\text { Comencé por } \\
\text { una } \\
\text { recomendación } \\
\text { de un familiar y } \\
\text { por mi afinidad } \\
\text { con este } \\
\text { deporte desde } \\
\text { que tengo uso } \\
\text { de razón. }\end{array}$ \\
\hline $\begin{array}{l}\text { 2. ¿Cree que } \\
\text { hay machismo } \\
\text { en el fútbol? } \\
\text { (¿Cómo } \\
\text { consideras que } \\
\text { son las } \\
\text { agresiones, } \\
\text { hacia los } \\
\text { árbitros o hacia } \\
\text { la mujer?) }\end{array}$ & $\begin{array}{l}\text { Sí, en todos los } \\
\text { deportes, pero } \\
\text { en el fútbol es el } \\
\text { que más se da, } \\
\text { porque siempre } \\
\text { se ha } \\
\text { considerado de } \\
\text { hombres, y } \\
\text { aunque este } \\
\text { tema vaya } \\
\text { avanzando } \\
\text { sigue habiendo } \\
\text { machismo, ya } \\
\text { que incluso } \\
\text { cuando ven a } \\
\text { una mujer } \\
\text { arbitrar hay } \\
\text { muchas caras } \\
\text { de } \\
\text { sorprendidos. }\end{array}$ & $\begin{array}{l}\text { Sí, aunque el } \\
\text { avance con } \\
\text { respecto a este } \\
\text { tema ha ido } \\
\text { mejorando, } \\
\text { pero pienso que } \\
\text { en el deporte } \\
\text { en general es } \\
\text { donde más } \\
\text { podemos llegar } \\
\text { a sufrir el } \\
\text { machismo, y } \\
\text { más aún si } \\
\text { cabe, en el } \\
\text { fútbol, puesto } \\
\text { que sigue } \\
\text { siendo } \\
\text { considerado un } \\
\text { deporte de } \\
\text { hombres. }\end{array}$ & $\begin{array}{l}\text { Algunas veces } \\
\text { sí y otras no, } \\
\text { pero en general } \\
\text { a distancia se } \\
\text { sabe que no se } \\
\text { trata en el tema } \\
\text { del fútbol, ya } \\
\text { seas futbolista o } \\
\text { arbitra, de la } \\
\text { misma manera. } \\
\text { Normalmente } \\
\text { suelen ser } \\
\text { verbales, algún } \\
\text { comentario } \\
\text { despectivo } \\
\text { como, por } \\
\text { ejemplo: Al ser } \\
\text { chicas no se os } \\
\text { da bien esta } \\
\text { profesión, esto }\end{array}$ & $\begin{array}{l}\text { Si, hay mucho } \\
\text { machismo, } \\
\text { pero lo más } \\
\text { grave de todo } \\
\text { es que yo lo } \\
\text { he recibido por } \\
\text { parte de } \\
\text { mujeres } \\
\text { aficionadas o } \\
\text { madres de } \\
\text { niños que } \\
\text { jugaban. } \\
\text { Pienso que el } \\
\text { machismo } \\
\text { está inmerso } \\
\text { en la sociedad } \\
\text { y en el fútbol } \\
\text { como parte de } \\
\text { esta, pero aún } \\
\text { es más fácil }\end{array}$ & $\begin{array}{l}\text { Evidentemente } \\
\text { pienso que hay } \\
\text { machismo en el } \\
\text { fútbol, y quizás } \\
\text { más en el } \\
\text { arbitraje. } \\
\text { Habiendo vivido } \\
\text { los dos } \\
\text { extremos, tanto } \\
\text { de futbolista } \\
\text { como de } \\
\text { árbitro, existe } \\
\text { un machismo } \\
\text { discriminatorio } \\
\text { contra las } \\
\text { mujeres en este } \\
\text { ámbito. }\end{array}$ \\
\hline
\end{tabular}




\begin{tabular}{|c|c|c|c|c|c|}
\hline & $\begin{array}{l}\text { Nunca he } \\
\text { sufrido una } \\
\text { agresión física, } \\
\text { pero verbal } \\
\text { hacia la mujer } \\
\text { muchas, ya que } \\
\text { parece que no } \\
\text { está bien visto } \\
\text { que las mujeres } \\
\text { arbitren a } \\
\text { hombres. }\end{array}$ & $\begin{array}{l}\text { Personalmente, } \\
\text { nunca he } \\
\text { llegado a sufrir } \\
\text { agresión física. } \\
\text { Pero sí } \\
\text { considero } \\
\text { agresión todos } \\
\text { los insultos que } \\
\text { recibimos, tanto } \\
\text { machistas } \\
\text { como de } \\
\text { cualquier otro } \\
\text { tipo. }\end{array}$ & $\begin{array}{l}\text { es para } \\
\text { hombres'. }\end{array}$ & $\begin{array}{l}\text { mostrar este } \\
\text { tipo de } \\
\text { conductas en } \\
\text { un mundo } \\
\text { entendido para } \\
\text { hombres por } \\
\text { parte de esta } \\
\text { sociedad. } \\
\text { Todos los } \\
\text { insultos que } \\
\text { nos dicen es } \\
\text { agresión hacia } \\
\text { la mujer, } \\
\text { porque son } \\
\text { insultos } \\
\text { machistas. }\end{array}$ & \\
\hline $\begin{array}{l}\text { 3. ¿Ha tenido } \\
\text { alguna dificultad } \\
\text { durante la } \\
\text { formación por el } \\
\text { hecho de ser } \\
\text { mujer? }\end{array}$ & & $\begin{array}{l}\text { La exigencia a } \\
\text { nivel físico, } \\
\text { actualmente } \\
\text { hay más } \\
\text { accesibilidad y } \\
\text { oportunidades. }\end{array}$ & $\begin{array}{l}\text { Ninguna, ya que } \\
\text { los que trabajan } \\
\text { contigo y } \\
\text { entienden la } \\
\text { situación de la } \\
\text { mujer, hacen } \\
\text { más fácil que } \\
\text { lleves a cabo lo } \\
\text { que } \\
\text { verdaderamente } \\
\text { te gusta. }\end{array}$ & $\begin{array}{l}\text { Sí, he visto } \\
\text { como a } \\
\text { compañeras } \\
\text { por el hecho } \\
\text { de ser chicas } \\
\text { e incluso a mí } \\
\text { se le han dado } \\
\text { partidos } \\
\text { menos } \\
\text { complicados, } \\
\text { por ejemplo. }\end{array}$ & $\begin{array}{l}\text { Desde que } \\
\text { comencé he } \\
\text { tenido } \\
\text { impedimentos } \\
\text { de diversos } \\
\text { motivos en el } \\
\text { mundo del } \\
\text { arbitraje, pero } \\
\text { considero, que } \\
\text { ocurre en esto, } \\
\text { como, en tantas } \\
\text { otras cosas de } \\
\text { la vida } \\
\text { cotidiana, hay } \\
\text { personas que } \\
\text { te ayudan a } \\
\text { avanzar y otras } \\
\text { que ni siquiera } \\
\text { se molestan en } \\
\text { eso. }\end{array}$ \\
\hline $\begin{array}{l}\text { 4. ¿Qué tipo de } \\
\text { dificultades ha } \\
\text { encontrado en } \\
\text { su experiencia } \\
\text { como arbitra? } \\
\text { (¿Qué tipo de } \\
\text { rostro percibe } \\
\text { cuando llega al } \\
\text { campo y ven } \\
\text { que es una } \\
\text { mujer?) }\end{array}$ & $\begin{array}{l}\text { Quizás he } \\
\text { echado en falta } \\
\text { más apoyo de } \\
\text { compañeros } \\
\text { que están } \\
\text { metidos en este } \\
\text { mundo. }\end{array}$ & $\begin{array}{l}\text { Falta de tiempo } \\
\text { para poder } \\
\text { estudiar o } \\
\text { entrenar, ya } \\
\text { que requiere un } \\
\text { alto nivel de } \\
\text { compromiso. } \\
\text { Ya es mucho } \\
\text { más } \\
\text { normalizado, al } \\
\text { ser un número } \\
\text { muy reducido } \\
\text { las que } \\
\text { actualmente } \\
\text { estamos } \\
\text { federadas, la } \\
\text { mayoría de los } \\
\text { clubes nos } \\
\text { conocen. }\end{array}$ & $\begin{array}{l}\text { En sí, no veo } \\
\text { dificultades, } \\
\text { simplemente } \\
\text { cuando tienes } \\
\text { un partido antes } \\
\text { de salir al } \\
\text { campo pensar el } \\
\text { qué nos vamos } \\
\text { a encontrar o el } \\
\text { qué dirán, pero } \\
\text { no es ningún } \\
\text { problema. } \\
\text { Algunos se } \\
\text { quedan } \\
\text { sorprendidos, } \\
\text { otros no tienen } \\
\text { problema, es } \\
\text { decir, lo ven } \\
\text { como algo } \\
\text { normal como } \\
\text { debería verse } \\
\text { hoy en día, pero } \\
\text { claro en un } \\
\text { campo siempre } \\
\text { hay una } \\
\text { persona que no } \\
\text { está de acuerdo } \\
\text { con que sea una } \\
\text { mujer la que } \\
\text { arbitre. }\end{array}$ & $\begin{array}{l}\text { He llegado a } \\
\text { recibir } \\
\text { comentarios } \\
\text { del tipo: "Yo } \\
\text { no te voy a } \\
\text { decir nada, } \\
\text { pero pienso } \\
\text { que una mujer } \\
\text { no debería de } \\
\text { pitar partidos } \\
\text { de hombres" } \\
\text { He encontrado } \\
\text { muchas caras } \\
\text { de sorpresa al } \\
\text { verme allí. }\end{array}$ & $\begin{array}{l}\text { Comenzando } \\
\text { por la } \\
\text { desigualdad en } \\
\text { la confianza } \\
\text { que depositan } \\
\text { en un hombre y } \\
\text { una mujer en el } \\
\text { mundo del } \\
\text { arbitraje hasta } \\
\text { impedimentos } \\
\text { en los campos } \\
\text { de fútbol por el } \\
\text { solo hecho de } \\
\text { ser mujer por } \\
\text { parte de } \\
\text { directivos o } \\
\text { incluso niños o } \\
\text { padres. } \\
\text { Encuentro } \\
\text { caras de } \\
\text { sorpresa por } \\
\text { pitar a hombres }\end{array}$ \\
\hline
\end{tabular}




\begin{tabular}{|c|c|c|c|c|c|}
\hline $\begin{array}{l}\text { 5. ¿Cómo se } \\
\text { siente durante } \\
\text { un partido? } \\
\text { (cuando oye } \\
\text { que le agreden } \\
\text { verbalmente } \\
\text { con frases } \\
\text { amenazantes, } \\
\text { despectivas o } \\
\text { insultos) }\end{array}$ & $\begin{array}{l}\text { Me siento mal, } \\
\text { puesto que hay } \\
\text { veces que } \\
\text { parece que los } \\
\text { árbitros no } \\
\text { pueden } \\
\text { equivocarse. } \\
\text { Incluso cuando } \\
\text { arbitras bien, } \\
\text { hay gente por } \\
\text { detrás que no } \\
\text { deja de insultar. } \\
\text { El que una esté } \\
\text { dentro del } \\
\text { terreno de juego } \\
\text { y tenga que } \\
\text { dirigir un partido } \\
\text { y otro esté en la } \\
\text { grada pudiendo } \\
\text { decir lo que } \\
\text { quiera, no le da } \\
\text { el derecho de } \\
\text { poder insultar a } \\
\text { la árbitra u } \\
\text { cualquier } \\
\text { jugador. }\end{array}$ & $\begin{array}{l}\text { En ocasiones } \\
\text { mal, al ver la } \\
\text { falta de } \\
\text { educación y de } \\
\text { empatía que } \\
\text { existe en la } \\
\text { sociedad. } \\
\text { Sobre todo, en } \\
\text { las categorías } \\
\text { del futbol base, } \\
\text { cuando veo } \\
\text { incluso a niños } \\
\text { mandando a } \\
\text { callar a los } \\
\text { padres. }\end{array}$ & $\begin{array}{l}\text { Te sientes } \\
\text { incómoda, tú } \\
\text { solo quieres } \\
\text { disfrutar de lo } \\
\text { que te gusta, de } \\
\text { un deporte que } \\
\text { es tanto para } \\
\text { hombres como } \\
\text { mujeres. } \\
\text { Entonces } \\
\text { sientes rabia e } \\
\text { impotencia de } \\
\text { no poder y dejar } \\
\text { claro que al } \\
\text { igual que los } \\
\text { hombres, las } \\
\text { mujeres también } \\
\text { podemos } \\
\text { hacerlo. Antes } \\
\text { de salir al } \\
\text { campo sientes } \\
\text { la curiosidad del } \\
\text { "qué dirán" y } \\
\text { nervios }\end{array}$ & $\begin{array}{l}\text { Siento rabia y } \\
\text { frustración por } \\
\text { no poder } \\
\text { decirle a esas } \\
\text { personas que } \\
\text { sean } \\
\text { coherentes } \\
\text { con lo que } \\
\text { dicen. }\end{array}$ & $\begin{array}{l}\text { Realmente } \\
\text { cuantos más } \\
\text { años pasan } \\
\text { desde que } \\
\text { empiezas, te } \\
\text { das cuenta que } \\
\text { no merece la } \\
\text { pena escuchar } \\
\text { los insultos de } \\
\text { una persona } \\
\text { frustrada que } \\
\text { amenaza o } \\
\text { insulta desde el } \\
\text { anonimato a un } \\
\text { niño o una } \\
\text { chica que son } \\
\text { árbitros. } \\
\text { Actualmente ni } \\
\text { siquiera } \\
\text { escucho las } \\
\text { críticas de } \\
\text { estas personas, } \\
\text { pero sí que es } \\
\text { cierto que, al } \\
\text { principio llegas } \\
\text { a sentir } \\
\text { frustración } \\
\text { porque te } \\
\text { quieren hacer } \\
\text { ver } \\
\text { constantemente } \\
\text { que lo haces } \\
\text { todo mal y } \\
\text { ponen en duda } \\
\text { tu trabajo y } \\
\text { sacrificio. } \\
\end{array}$ \\
\hline $\begin{array}{l}\text { 6. ¿Qué } \\
\text { emociones } \\
\text { siente tras éste? }\end{array}$ & $\begin{array}{l}\text { Inseguridad, } \\
\text { tras escuchar } \\
\text { tantos "fallos" } \\
\text { que dicen que } \\
\text { se están } \\
\text { cometiendo, } \\
\text { rabia e } \\
\text { impotencia }\end{array}$ & $\begin{array}{l}\text { Impotencia y } \\
\text { rabia }\end{array}$ & $\begin{array}{l}\text { Después del } \\
\text { partido, } \\
\text { simplemente } \\
\text { estoy a gusto } \\
\text { con mi trabajo } \\
\text { realizado, yo } \\
\text { creo que la } \\
\text { tensión es antes } \\
\text { y durante el } \\
\text { partido. } \\
\text { Después sientes } \\
\text { relajación }\end{array}$ & $\begin{array}{l}\text { A veces me } \\
\text { siento muy } \\
\text { bien porque a } \\
\text { pesar de las } \\
\text { críticas, siento } \\
\text { que he hecho } \\
\text { un buen } \\
\text { trabajo, pero sí } \\
\text { que es cierto } \\
\text { que, en } \\
\text { ocasiones te } \\
\text { hacen } \\
\text { replantearte si } \\
\text { de verdad } \\
\text { sirves para } \\
\text { esto, y si } \\
\text { merece la } \\
\text { pena aguantar } \\
\text { todas las } \\
\text { críticas e } \\
\text { insultos. } \\
\text { Sí que es } \\
\text { cierto que soy } \\
\text { una persona } \\
\text { que corta este } \\
\text { tipo de } \\
\text { conductas } \\
\text { rápidamente, } \\
\text { incluso en el } \\
\text { caso del }\end{array}$ & $\begin{array}{l}\text { Ahora podría } \\
\text { asegurar que } \\
\text { siento } \\
\text { satisfacción por } \\
\text { seguir haciendo } \\
\text { lo que quiero y } \\
\text { me gusta, a } \\
\text { pesar de tantos } \\
\text { impedimentos }\end{array}$ \\
\hline
\end{tabular}




\begin{tabular}{|c|c|c|c|c|c|}
\hline & & & & $\begin{array}{l}\text { público y } \\
\text { aficionados, } \\
\text { llamando a las } \\
\text { fuerzas del } \\
\text { orden público } \\
\text { para que } \\
\text { retiren a esas } \\
\text { personas de } \\
\text { las } \\
\text { instalaciones } \\
\text { deportivas. }\end{array}$ & \\
\hline $\begin{array}{l}\text { 7. ¿Qué le } \\
\text { funciona para } \\
\text { superar } \\
\text { emocionalmente } \\
\text { los malos } \\
\text { momentos? }\end{array}$ & $\begin{array}{l}\text { Para superar } \\
\text { esos momentos } \\
\text { lo que pienso es } \\
\text { que si me inicié } \\
\text { desde un } \\
\text { principio en este } \\
\text { mundo es } \\
\text { porque me } \\
\text { gusta y nadie } \\
\text { tiene el poder } \\
\text { de quitarme esa } \\
\text { ilusión de poder } \\
\text { seguir } \\
\text { arbitrando que } \\
\text { es lo que } \\
\text { verdaderamente } \\
\text { da fuerzas para } \\
\text { seguir }\end{array}$ & $\begin{array}{l}\text { Me siento } \\
\text { orgullosa de ser } \\
\text { árbitra y mujer. } \\
\text { Estamos en un } \\
\text { mundo de } \\
\text { valientes. } \\
\text { Donde cada día } \\
\text { es un } \\
\text { aprendizaje e } \\
\text { intento pensar } \\
\text { que por esos } \\
\text { malos } \\
\text { momentos no } \\
\text { hay que tirar } \\
\text { por tierra todas } \\
\text { las cosas } \\
\text { positivas que } \\
\text { me aporta el } \\
\text { arbitraje }\end{array}$ & $\begin{array}{l}\text { Pues pienso en } \\
\text { lo que me gusta, } \\
\text { que lo que estoy } \\
\text { haciendo me } \\
\text { satisface y me } \\
\text { llena. }\end{array}$ & $\begin{array}{l}\text { Me funciona } \\
\text { pensar lo } \\
\text { mucho que me } \\
\text { gusta este } \\
\text { mundo y lo } \\
\text { mucho que } \\
\text { disfruto } \\
\text { arbitrando, así } \\
\text { como el afán } \\
\text { de superación, } \\
\text { ya que cada } \\
\text { día trabajo } \\
\text { para llegar } \\
\text { más lejos en } \\
\text { este mundo }\end{array}$ & $\begin{array}{l}\text { El apoyo de mis } \\
\text { compañeros } \\
\text { más cercano y } \\
\text { el amor hacia } \\
\text { este deporte es } \\
\text { lo que me } \\
\text { ayuda a seguir } \\
\text { temporada tras } \\
\text { temporada } \\
\text { aguantando el } \\
\text { arbitraje y todo } \\
\text { lo que esto } \\
\text { conlleva }\end{array}$ \\
\hline $\begin{array}{l}\text { 8. ¿Qué } \\
\text { soluciones cree } \\
\text { que hay para } \\
\text { que mejore esta } \\
\text { situación? }\end{array}$ & $\begin{array}{l}\text { Hacer } \\
\text { consciente a la } \\
\text { sociedad de lo } \\
\text { que la mujer } \\
\text { puede realizar. } \\
\text { Cambiar la } \\
\text { mentalidad, } \\
\text { inclusive de las } \\
\text { propias mujeres } \\
\text { que ven el } \\
\text { fútbol. Mayor } \\
\text { difusión en los } \\
\text { medios de } \\
\text { comunicación, } \\
\text { ya que siempre } \\
\text { son hombres lo } \\
\text { que salen en la } \\
\text { sección de } \\
\text { deportes }\end{array}$ & $\begin{array}{l}\text { Es cuestión de } \\
\text { educación de la } \\
\text { sociedad. } \\
\text { También veo } \\
\text { muy positiva la } \\
\text { publicidad por } \\
\text { parte de los } \\
\text { medios de } \\
\text { comunicación }\end{array}$ & $\begin{array}{l}\text { No creo que } \\
\text { haya solución } \\
\text { para el tema } \\
\text { contra la mujer } \\
\text { porque siempre } \\
\text { va a estar la } \\
\text { persona que } \\
\text { piense que la } \\
\text { mujer no sirve } \\
\text { para nada, solo } \\
\text { para tareas } \\
\text { domésticas. Lo } \\
\text { que si se podría } \\
\text { hacer es seguir } \\
\text { motivando a las } \\
\text { mujeres para } \\
\text { que hagan lo } \\
\text { que les guste, } \\
\text { aunque sea un } \\
\text { deporte que } \\
\text { prevalece en } \\
\text { hombres. Tiene } \\
\text { que haber más } \\
\text { mujeres que se } \\
\text { le lancen a este } \\
\text { mundo o } \\
\text { cualquiera sin } \\
\text { pensar el qué } \\
\text { dirán. Cuantas } \\
\text { más mujeres } \\
\text { haya } \\
\text { dispuestas, más } \\
\text { idea se va a } \\
\text { hacer el mundo } \\
\text { entero de que } \\
\text { las mujeres } \\
\text { tienen las }\end{array}$ & $\begin{array}{l}\text { Pensar en que } \\
\text { ser árbitros es } \\
\text { algo que te } \\
\text { encanta, y } \\
\text { tener la } \\
\text { sensación de } \\
\text { que lo has } \\
\text { hecho bien y } \\
\text { que has sido } \\
\text { lo más justa } \\
\text { posible. } \\
\text { Pensar } \\
\text { también en } \\
\text { todo el trabajo } \\
\text { y el sacrificio } \\
\text { que conlleva la } \\
\text { preparación } \\
\text { para ser } \\
\text { árbitros y } \\
\text { cuánto merece } \\
\text { la pena } \\
\text { disfrutar como } \\
\text { lo haces } \\
\text { superando } \\
\text { retos y } \\
\text { barreras, } \\
\text { aunque haya } \\
\text { agentes } \\
\text { externos que } \\
\text { intenten } \\
\text { arrebatarte } \\
\text { ese momento. }\end{array}$ & $\begin{array}{l}\text { Pienso que el } \\
\text { problema que } \\
\text { se ve en los } \\
\text { campos de } \\
\text { fútbol es, un } \\
\text { problema social } \\
\text { y educativo. } \\
\text { Debería } \\
\text { comenzarse } \\
\text { eliminando todo } \\
\text { el odio que se } \\
\text { desprende y } \\
\text { disfrutando } \\
\text { realmente del } \\
\text { deporte. } \\
\text { Entender que } \\
\text { no es más que } \\
\text { un juego desde } \\
\text { las categorías } \\
\text { inferiores. } \\
\text { Además de que } \\
\text { todos somos } \\
\text { personas y nos } \\
\text { equivocamos, } \\
\text { tanto futbolistas } \\
\text { como árbitros. }\end{array}$ \\
\hline
\end{tabular}




\begin{tabular}{|l|l|l|l|}
\hline & & mismas & posibilidades y \\
& & los mismos \\
derechos que & & \\
& & & \\
\hline
\end{tabular}

\section{Diario:}

En este anexo se muestra los resultados de las reflexiones por parte de la participante 4, tras cada partido arbitrado

Partido 1: Tras finalizar el partido, siento impotencia y tristeza por los comentarios escuchados. Al principio, desde la grada se escuchaban gritos hacia los 3 árbitros, (2 liniers, uno de ellos yo, chica, y un árbitro), pero conforme el partido avanzaba solo se centraba un solo hombre en insultarme a mí por el hecho de ser mujer, teniendo que escuchar "las mujeres no valen para eso", "tú lo que tendrías es que estar estudiando y sacándote una carreara".

Partido 2: Tras el punto y final del partido, y estando este ya, bastante tenso, los jugadores van a por el árbitro, siendo yo, en este caso asistente, empiezan a decirle que qué hemos hecho, que no sabemos pitar, que no tenemos vergüenza. Tras la entrada en el vestuario para la realización del acta, salimos y del terreno y nos estaban esperando allí para encararse con nosotros, viniendo de forma agresiva, finalmente no pasó nada, pero son estos momentos en los que sientes miedo. Miedo por saber que pueden agredirte y sólo por estar haciendo tu trabajo de la mejor manera posible.

Partido 3: Tras la finalización de este partido de benjamines es cuando verdaderamente me doy cuenta de lo mucho que me gusta este mundo, cuando veo disfrutar a niños pequeños jugar al fútbol, cuando veo que los entrenadores no sólo quieren ganar, sino que aprendan, es ahí cuando pienso lo feliz que soy arbitrando.

Partido 4: Tras la finalización del partido, y siendo este, segunda división femenina, nos dieron la enhorabuena por como lo habíamos hecho las tres árbitras. El partido estuvo disputado, escuchamos protestas, pero no más allá de la tensión que causa el fútbol y el estar jugándose un puesto de descenso. Aun así, al acabar el partido ambos equipos nos felicitaron, es por esto que sentí satisfacción por haber hecho un buen trabajo.

Partido 5: En este partido todo iba bien, hasta que un padre se metió con el entrenador del equipo contrario de su hijo, ambos empezaron a discutir por un simple balón que el entrenador no había echado con rapidez al campo. Aunque esto no sea insultos hacia mi persona, también siento tristeza al escuchar a padres de niños que no tenían ni 7 años, insultar al entrenador, cuando sus propios hijos lo están escuchando todo.

Partido 6: Durante todo el partido los jugadores estuvieron quejándose porque supuestamente todo era falta y no pitaba nada. Una de las veces pito falta hacia el equipo contrario y se me encaró un jugador del equipo contrario, diciéndome con los brazos en alto: ¿qué estás pitando? ¿Te sabes el reglamento? Los jugadores, los padres y los entrenadores, son muchas las veces que cuestionan nuestro trabajo, cuando llevamos razón en cosas de reglamento, ya que verdaderamente somos nosotras las que nos sabemos el reglamento y por eso estamos ahí, porque hemos pasado nuestro examen para que encima nos recriminen todo, sintiendo rabia por ello. 
Partido 7: En este partido no hubo insultos, solo hubo caras de sorpresa al comienzo por ver pitar a una mujer. Finalizó el partido y pude irme contenta a casa, puesto que no fue un partido complicado ni hubo grandes protestas.

Partido 8: Durante este partido sólo escuchaba protestas de los jugadores, puesto que según ellos el otro equipo cada vez que recibía el balón para lanzar, estaban en fuera de juego. Hay muchas protestas por este motivo. Son muchos los jugadores que protestan el fuera de juego por protestar, pero llega un momento en el que me canso y tras tantas protestas llego a tener inseguridad, aun haciendo bien mi trabajo.

Partido 9: Este partido lo empecé estando baja de ánimos, algo que perjudica a la hora de pitar puesto que a lo mejor no estoy tan pendiente como debería de todo lo que ocurre, centrándome sólo en el partido, pero conforme avanzó me iba sintiendo mejor. Ese partido fue tranquilo y fue como una manera que tuve de despejarme haciendo lo que me gusta.

Partido 10: En este partido tuve que pitar benjamines y me llamó la atención como me miraban todos los niños, como decían: "anda mira si es una árbitra" y cómo el entrenador contestó: "claro las mujeres también pitan y seguro que lo hacen hasta mejor que los hombres, así que no quiero escuchar ninguna queja". Al igual que hay entrenadores que no educan a sus jugadores, este era todo lo contrario, estaba inculcándole a los niños desde bien pequeños que las mujeres también desempeñamos este papel. Es por ello por lo que me fui con mucha satisfacción de este partido, viendo como cada vez hay más entrenadores preocupados de inculcar valores y haciendo que no prime solo la competitividad, sino la educación y el compañerismo entre todos. 
Tabla. Resumen de las emociones positivas y negativas experimentadas por la participante 4, tras 10 partidos.

\begin{tabular}{|c|c|c|c|c|c|c|c|c|c|c|}
\hline & 1 & 2 & 3 & 4 & 5 & 6 & 7 & 8 & 9 & 10 \\
\hline $\begin{array}{l}\text { Emociones } \\
\text { positivas }\end{array}$ & & & Felicidad & Alegría & & & Satisfacción & & Emoción & Felicidad \\
\hline $\begin{array}{l}\text { Causas } \\
\text { emociones } \\
\text { positivas }\end{array}$ & & & $\begin{array}{l}\text { Ver a } \\
\text { niños } \\
\text { pequeños } \\
\text { disfrutar }\end{array}$ & $\begin{array}{l}\text { Felicitaciones } \\
\text { por parte de } \\
\text { jugadoras }\end{array}$ & & & $\begin{array}{l}\text { Nada de } \\
\text { protestas }\end{array}$ & & $\begin{array}{l}\text { Hacer lo } \\
\text { que de } \\
\text { verdad } \\
\text { me } \\
\text { gusta }\end{array}$ & $\begin{array}{l}\text { Entrenado } \\
\text { res que } \\
\text { educan a } \\
\text { sus } \\
\text { jugadores }\end{array}$ \\
\hline $\begin{array}{l}\text { Emociones } \\
\text { negativas }\end{array}$ & Impotencia & Miedo & & & Tristeza & Impotencia & & Inseguridad & & \\
\hline $\begin{array}{l}\text { Causas } \\
\text { emociones } \\
\text { negativas }\end{array}$ & $\begin{array}{l}\text { Numerosas } \\
\text { recriminaciones } \\
\text { hacia mi } \\
\text { persona. }\end{array}$ & $\begin{array}{l}\text { Encararse } \\
\text { determinados } \\
\text { jugadores y } \\
\text { esperarnos en } \\
\text { la salida }\end{array}$ & & & $\begin{array}{l}\text { Escuchar } \\
\text { padres de } \\
\text { jugadores } \\
\text { insultar al } \\
\text { entrenador } \\
\text { contrario }\end{array}$ & $\begin{array}{l}\text { Juzgar mi } \\
\text { trabajo }\end{array}$ & & $\begin{array}{l}\text { Muchas } \\
\text { protestas }\end{array}$ & & \\
\hline
\end{tabular}

